\title{
Transgastric Pancreatic Debridement: a Step-by-step Guide to a Single-staged Procedure for Walled-off Pancreatic Necrosis
}

\section{Thomas K. Maatman ${ }^{1} \cdot$ Nicholas J. Zyromski ${ }^{1}$}

Received: 27 May 2019 / Accepted: 14 August 2019 / Published online: 3 March 2020

(C) 2020 The Society for Surgery of the Alimentary Tract

\begin{abstract}
Treatment of necrotizing pancreatitis (NP) requiring intervention must be tailored to each patient's individual clinical situation. Surgical transgastric debridement addresses necrosis confined to the lesser sac with the option to perform cholecystectomy in a single intervention. ${ }^{1}$ With proper patient selection, this technique achieves resolution of necrosis in $90 \%$ of patients. ${ }^{2}$ In the setting of disconnected pancreatic duct syndrome, cystogastrostomy achieves pancreatic tail drainage with durable long-term success in $80 \%$ of patients. ${ }^{3}$ This case presentation and step-by-step walkthrough demonstrates critical technical aspects and decision-making for surgical transgastric debridement of walled-off pancreatic necrosis.
\end{abstract}

Keywords Necrotizing pancreatitis $\cdot$ Debridement $\cdot$ Transgastric debridement $\cdot$ Operative debridement

\section{References}

1. Zyromski NJ, Nakeeb A, House MG, Jester AL. Transgastric Pancreatic Necrosectomy: How I Do It. J Gastrointest Surg. 2016;20(2):445-9. https://doi.org/10.1007/s11605-015-3058-y.

2. Driedger M, Zyromski NJ, Visser BC, Jester A, Sutherland FR, Nakeeb A, Dixon E, Dua MM, House MG, Worhunsky DJ, Munene G, Ball CG. Surgical Transgastric Necrosectomy for Necrotizing Pancreatitis: A Single-stage Procedure for Walled-off Pancreatic Necrosis. Ann Surg. 2018. https://doi.org/10.1097/SLA. 0000000000003048.
3. Dua MM, Jensen CW, Friedland S, Worth PJ, Poultsides GA, Norton JA, Park WG, Visser BC. Isolated pancreatic tail remnants after transgastric necrosectomy can be observed. J Surg Res. 2018;231: 109-15. https://doi.org/10.1016/j.jss.2018.05.020.

Publisher's Note Springer Nature remains neutral with regard to jurisdictional claims in published maps and institutional affiliations.
Electronic supplementary material The online version of this article (https://doi.org/10.1007/s11605-019-04375-x) contains supplementary material, which is available to authorized users.

This work has been presented as a video presentation at the 2019 annual meeting of the Society for Surgery of the Alimentary Tract in San Diego, CA.

Nicholas J. Zyromski

nzyromsk@iupui.edu

1 Department of Surgery, Indiana University School of Medicine, 545 Barnhill Dr., EH 519, Indianapolis, IN 46202, USA 